\title{
Inheritance and Development of Commercial Culture in Zhejiang Province Based on "The Belt and Road"
}

\author{
Guoying Zhang \\ Zhejiang Business College, Hangzhou, China
}

Keywords: The Belt and Road; Zhejiang business culture; Inheritance and development

\begin{abstract}
The diligent and brave Zhejiang merchants created great economic value and bred unique business culture in its historic business activities. Firstly, the concept and content of The Belt and Road strategy are introduced in this article; Then the Zhejiang business culture is introduced; Next, the role of commercial culture in The Belt and Road strategy is analyzed; And Finally, the concrete ways of commercial culture inheritance and development in Zhejiang province are put forward.
\end{abstract}

\section{Introduction}

“The Belt and Road”(abbr B\&R)contain Land silk road and Maritime silk road which were Originated in ancient China.

As early as September 2013, Xi Jinping put forward the initiative of jointly building the silk road economic belt and the 21st century maritime silk road. And now, the B\&R strategy has become China's national top-level strategy.

"The Belt and Road" connects the three continents of Europe, Asia and Africa and the silk road economic belt by sea, forming a closed loop of sea and land. The strategy covers economic integration in southeast Asia and northeast Asia, and finally integrated into Europe, forming a general trend of economic integration of Eurasia.

\section{Double circulation and soft power theory}

\subsection{About double circulation theory}

At present, economic globalization makes world economic activities surpass country border. the world is connected into a unified large market through foreign trade, technology transfer, capital flow, services and other economic activities. Every country plays its own advantage in this market, so as to realize the optimized allocation of resources in the world.

From the end of the 20th century to the beginning of the 21st century, China rose in an unimaginable way, and its position in the world economy changed dramatically. The scale of China's economy is so large that the global trade structure is beginning to change, starting to form a double circulation structure.

The economics and trade relationship of China and west nation constitutes a circulation: China export product to West and import technique, funds and various high level service industry. This process makes the first circulation. The economics and trade relationship of China and other non-west nation constitutes another circulation: China imports original material from these nation, export finished product, this is the second circulation.

These 2 cycles are connected through China: Under the structure of "center-periphery", western nation directly carries on trade with developing country, but the most basic power of global economy development still keeps coming from west, and the great development of china's manufacturing industry is also pulled by western creative economy. So the west is still the main center, but China has already grown to become a pair center and has become a world factory. This further brought the transformation of the world's economic trade structure, and turn "center-periphery" structure into "double circulation" structure. 


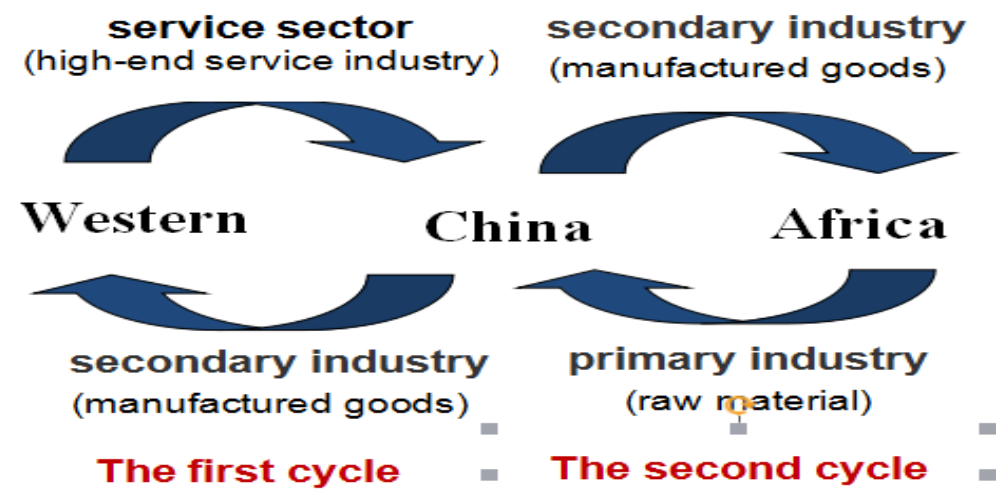

Figure 1. Double circulation

\subsection{Soft power theory}

Soft power refers to a city or region's culture, values, social system and other factors affecting its own development potential and inspiration, it's relative to the gross domestic product, urban infrastructure and other hard power.

Hard power is a visible and tangible material force; soft power is a spiritual force, including political, cultural, diplomatic and other soft elements. These two are both closely linked and distinct from each other. Hard power is the tangible carrier and materialization of soft power, , and soft power is the invisible extension of hard power.

In the globalization, information revolution and network era, soft power has the same or even more important position.

China has a long history and splendid culture, its soft power base is strong. China should constantly improve its level of soft power and further strengthen exchanges and communication with other countries in the fields of culture, tourism, academia, and so on, so as to enable its culture, life style, values as well as political system are attractive to the people of other countries and play the role of the soft power of a country.

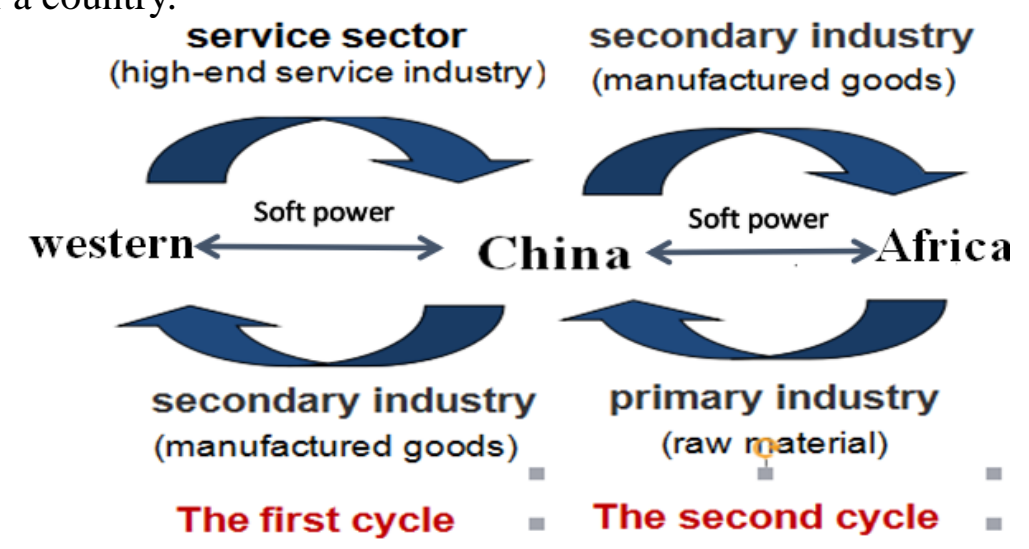

Figure 2. Triple circulation

\section{The role of commercial culture in " $B \& R$ " strategy}

Commercial culture has a long history with business practice. It includes commercial spirit culture, commodity culture, brand, trade name, trademark culture, marketing culture, business ethics culture, business environment culture and so on.

In the long course of world culture and history, various countries and nationalities along the Silk Road have gradually formed different commercial cultures, and they have constantly been developed and innovated on this basis.

\subsection{Commercial culture is soft power}

Commercial culture is the soft power that constitutes comprehensive competition ability. 
Commercial culture is a variety of cultural phenomena in the field of commodity circulation, which makes economy and culture no longer present "two skins". As time goes by, the business model iterates over and over again. Under the background of the Belt and Road, facing the new economic situation, business culture must constantly adjust and innovate with the times. In the new era, the homogeneity of commercial competition forces business to create new ways, to increase commercial attraction and increase commercial profits through cultural activities.

\subsection{Commercial culture is the support of the implementation of " $B \& R$ " strategy}

As a kind of culture, commercial culture is established in the field of commodity circulation, which is a variety of cultural phenomena in this field; and it is a new fulcrum and power for China's economic and social development in the course of transformation. The competition of business must at last be the competition of culture.

Many opportunities and challenges must be faced during the implementation of "B\&R" strategy. The systems of the countries along the B\&R vary greatly, political situation changes constantly, economic development level is not balanced, ethnic and religious situation is complex, culture is multifarious and diverse. All these factors will be the severe challenge that must be faced in the process of advancing "B\&R” strategy.

Among these, the social risk brought by the differences in religion and culture is the first risk that Chinese enterprises must consider when "going out". From this point of view, business culture is the bridge for the implementation of "B\&R" strategy and the gateway of China to the outer world.

\section{Approaches of inheritance and development of Zhejiang business culture}

Zhejiang economy, as an important part of the Yangtze River Delta economy, plays an important role in China, with the advance of "B\&R" strategy, Zhejiang has been given a new role.

Business in Zhejiang has a long history. At present, economic development level of Zhejiang province ranks among the top in China, an important reason is that there are many unique cultural forces behind its economy.

With the coming of the information age, Zhejiang merchants are making a new interpretation of businessmen culture with their consistent sensitivity and quickness as well as the brand-new social values and cultural imagination.

Combing with "B\&R" strategy, we give some concrete approaches as follows.

\subsection{Adhering to win-win cooperation and optimizing resource allocation}

With the gradual deepening of "B\&R" strategy, Zhejiang should take this opportunity to promote industrial transformation and upgrading and create an economic and trade cooperation pioneer area, an "online silk road" pilot area and a trade and logistics hub area to build a new pattern of land and sea coordination, east and west exchange and north-south connectivity; and actively participate in "B\&R" project and open up new channels for international economic cooperation.

In the process of participating in international cooperation, Zhejiang enterprises are adept in "win-win cooperation" with local enterprises to optimize the allocation of resources. Related enterprises focus on core business and form a community of interests with local people.

Logistics transportation, raw material supply, sanitation and cleaning are outsourced to local enterprises and villagers In the process of international trade; e.g., China Huali group built Taichung Rayong industrial park in Thailand ten years ago,, and now it has gathered more than 80 enterprises such as Zhongce rubber and Fortis group. The park which is called "industrial Chinatown" of Thailand has paid a total of \$120 million in taxes and fees, and employed more than 20,000 people locally, among them Zhongce rubber, Chongqing Lifan and other enterprises have gone out from individual enterprises to the whole industrial chain in the upstream and downstream.

The deep integration and mutual benefit of countries along the Silk Road is the inevitable choice of resource optimization. In order to promote the Silk Road commercial culture inheritance and innovation, new concept of culture leading economy should be built up. As a bridge and the link, culture should act as the role of promoting active participation in the building of " $B \& R$ " and pushing 
regional economic development, so the Joint and coordinated development across regions, economic globalization and world multipolarization are realized.

\subsection{Taking advantage of resource advantage and developing pattern innovation}

Zhejiang is rich in resources of water, tourism etc., with broad prospects for tourism, Internet, cross-border e-commerce and cultural creative industries. In the implementation process of " B\&R" strategy, Self-Advantages should be exerted and innovative thinking and patterns should be actively developed.

In recent years, Zhejiang businessmen and entrepreneurs have been actively exploring the new field of cross-border e-commerce, the development mode of foreign trade is transformed and new space for national green coordinated development of "B\&R" countries is opened up.

Logistics between China and Russia is becoming faster and faster due to cross-border e-commerce technology and the delivery time of cross-border e-commerce from China to Russia has been shortened from one month to less than two weeks now. About 300 million packages are sent from China to Russia every year.

Meanwhile, by using Internet innovation, Internet financial enterprises such as Ant Financial and "B\&R" countries have cooperated in-depth in areas such as mobile payment and inclusive finance. For example, Ant Financial has invested in PAYTM_ _ an Indian mobile payment company, built an Indian version of Alipay, established Korea's first e-business bank in cooperation with 20 local institutions such as Korea Telecom (KT). With the rising of smartphone penetration rate among ordinary people in countries along "B\&R", the technology and application of mobile payment in China can enable more people to enjoy convenient and fast financial services.

\subsection{Developing both land and sea, speeding up integration into " $B \& R$ "}

Zhejiang is one of the starting points of the ancient silk road and an important part of the maritime silk road. Ningbo port is one of three shipping ports (the other two are Quanzhou port and Guangzhou port) on the maritime Silk Road. Ningbo port is located in the hinterland of Zhejiang where is "the home of silk" and "an abundant place", and it has played an important role in the export of goods such as silk, porcelain and tea.

In the early eastern Han dynasty, Ningbo had contacts with Japan. In Tang dynasty, Ningbo became one of China's big ports. In song dynasty, foreign trade developed rapidly in this region.

By virtue of the location advantages of facing the "maritime silk road" to the east and reaching the "land silk road" to the west, new platforms for connectivity have been established.

At present, Ningbo Zhoushan port has become the world's largest port. In March 2018, China's first 20,000-ton river and ocean direct ship was officially put into operation, connecting China's golden waterway — the Yangtze river and the port of Zhoushan in Ningbo, breaking the bottleneck of China's river and ocean combined transportation.

Besides, 8 transport lines have been developed in Zhejiang, including Yiwu-Madrid, Yiwu-Tehran, Yiwu-London, etc., and the China-Europe block train has the most operating lines and the most stable operation.

These trains can become a fast channel for China to engage in international trade with European countries such as the UK, further increasing the trade volume between China and countries along “B\&R”.

\section{Conclusion}

The areas along "B\&R" need not only the "hard" support of economic cooperation, but also the "soft" help of cultural cooperation.

Only by accelerating the inheritance and innovation of the Silk Road commercial culture and strengthening the commercial culture exchange and cooperation among the countries along the Silk Road can a common cultural language be formed, cultural resonance be aroused, mutual trust among the people be consolidated and the progress of human civilization and world peace be promoted.

Therefore, it is reasonable that we should proceed from a strategic and overall perspective, 
strengthen top-level design, deepen the reform and innovation of business culture system and mechanism, and take inheritance and innovation of business culture as an important measure to promote the construction of "B\&R".

\section{References}

[1] Kui Dai.Research on the Development of China's Cultural Industry under the Background of One Belt and Road. Modern Management Science, 2017(10):69-71.

[2] Liuhua Yang. Research on Inclusive Growth of Zhejiang Enterprises under the Background of One Belt and Road. Market Modernization, 2016(01):23-26.

[3] Jin-jin YE,Yan-di Wang. The Research on the Inheritance and Industrialization of Marine Intangible Cultural Heritage in the Background of "the Belt and Road"_— Take Zhoushan Ocean Immateriality Culture Relic Inherit as Example.

[4] Wang Ke, Jinsheng Liu."One Belt and Road "with e-commerce. Commercial Culture, 2017(02):12-15.

[5] Jianming Zhang. The Influence of Zhejiang Merchant Culture on the Construction of Harmonious Society. Commercial Culture, 2017(05):136-139. 